\title{
Collective agency among physics teachers: A case in China's curriculum reform
}

\author{
Guopeng Fu, Samson Nashon \\ Department of Curriculum and Pedagogy, University of British Columbia, Vancouver, Canada
}

Email address:

guopeng.fu@ubc.ca (G. Fu); samson.nashon@ubc.ca (S. Nashon)

To cite this article:

Guopeng Fu, Samson Nashon. Collective Agency among Physics Teachers: A Case in China's Curriculum Reform. International Journal of Secondary Education. Vol. 2, No. 6, 2014, pp. 94-101. doi: 10.11648/j.ijsedu.20140206.11

\begin{abstract}
This study explored how secondary physics teachers exercised their collective agency in the process of adopting and adapting to a nation-wide curriculum reform in China. Through an ethnographic approach and drawing on Social Cognitive Theory, physics teachers' collective agency was explored and interpreted. The results revealed that collective agency was a mediating bridge through which the discrepancies between reform mandates and teachers' pedagogies and curriculum interpretations were negotiated. Further, collective agency helped teachers to cope with uncertainties generated by the reform and offered mental supports. Moreover, the reform mandates undermined the traditional power hierarchy within teachers and thus stimulated teachers' collective agency. The study demonstrates the interdependent relations between collective agency and reform environment and has implications for theory, practice, curriculum, and research.
\end{abstract}

Keywords: Physics Teacher, Collective Agency, Chinese Curriculum Reform

\section{Introduction}

China has undertaken a large-scale educational reform encompassing curricular and pedagogical innovation at both elementary and secondary school levels (Erickson, Kang, Mitchell, \& Ryan, 2008; Guan \& Meng, 2007; Ministry of Education, 2001). Reform policies and guidelines require high schools to transition from a test-oriented only education to an all-round education (Zhu \& Kang, 2002). Teachers are often besieged by challenges, concerns, difficulties, and anxieties in the process of adopting any educational reform (Fullan \& Miles, 1992). The numerous reform mandates and recommendations are a heavy, sometimes even overwhelming burden to current high school teachers. In addition, science teaching in China, in particular physics, has traditionally featured direct lectures and rote memorization as the dominant teaching and learning methods (Song, 2006). The reform encourages teachers to incorporate new teaching strategies such as creating student-centered pedagogies consistent with the theme of the reform agenda. Thus, there is a need to investigate how physics teachers are responding to these reform efforts and negotiating their roles as individuals as well as groups within the typically conservative culture of physics pedagogy as well as the reform context.

Physics teachers in three Chinese suburban high schools participated in this study that explored how secondary physics teachers exercised their collective agency in the process of adopting and adapting to a nation-wide curriculum reform. We employed the notion of human agency (Bandura, 2006) to understand how high school physics teachers cope with Chinese curriculum reform as a group and how individual members and the external environment influence their collective agency. Collective agency is one mode of agency proposed in Social Cognitive Theory (Bandura, 2006). It refers to a group of people organizing their knowledge, skills, and resources together to achieve a communal goal and acts as a mediating tunnel negotiating the discrepancies between reform mandates and the local needs of the school and teachers. Moreover, collective agency helps teachers to cope with uncertainties generated by the reform and offers mental supports. The study was guided by the following research question:

How does the Chinese National Curriculum reform agenda shape physics teachers' collective agency and in turn, how does collective agency shape physics teachers'response to the reform?

This paper first lays out a brief description of the curriculum reform background featuring reform motivations, educational decentralization, and physics teaching in China. The notions of human agency and collective agency are then discussed from a social cognitive perspective (Bandura, 2006). An 
overview of the research methods and procedures is provided. The results and discussion section focuses on answering the research question as well as identifying other emergent themes which arose during the data analysis that are germane to the study.

\section{Reform Background}

The current curriculum reform in China is the eighth basic educational curriculum reform since the establishment of the People's Republic of China in 1949. It involves changes in all subjects in the K-12 school system. The reform includes changes in curriculum goals, structure, and content; teaching and learning approaches; and assessment and administrative structures (Zhu \& Kang, 2002).

\subsection{Physics Teaching}

In physics education, the Full-time High School Physics Curriculum Standard (MOE, 2003) is the national curriculum guideline for textbook writing, curriculum development, teaching, learning, and evaluation. According to the Standard, the transmission of physics content is no longer the central feature of the physics curriculum. Knowledge, scientific methods, and values are equally important in the new curriculum. It stresses students' active learning and inquiry. Students should play a leading role in physics classes and teachers should play supporting roles. The process of inquiry is more important than getting the correct answer. Teachers are encouraged to explore student thoughts, pay attention to what students already know, and monitor their thinking process. The new curriculum considers that knowledge is built through the interactions among teachers, students and textbooks. It also emphasizes physics knowledge applications such as interdisciplinary application and physics in daily life. Students take more responsibility for their learning and knowledge is generated through discussion and debates. Teachers are empowered in developing the curriculum that takes into account their own student needs. At the same time, teachers need to give up some power in controlling the class and molding student learning. How physics teachers make choices about their professional practice in negotiating the changing power dynamic in the new curriculum will reflect how teacher agency plays out in these complex social contexts.

\section{Theoretical Framework}

This study employed the Social Cognitive Theory (Bandura, 2006) to understand and interpret how Chinese physics teachers, as individuals and as groups, are responding to the reform efforts and negotiating their roles as change agents. According to Bandura, human agency is "the evolutionary emergence of advanced symbolizing capacity [enabling] humans to transcend the dictates of their immediate environment and [making] them unique in their power to shape their life circumstances and the courses their lives take" (p164). Teacher (human) agency juxtaposed both teachers' subjectivity and the reform environment. Teachers are able to shape and be shaped by their immediate environment (Bandura, 2006; Giddens, 1984; Pignatelli, 1993). Agency is not necessarily against social structure. It is the recognition of one's capacity as well as the surroundings and making decisions and taking actions under such recognition. Therefore, teacher agency in this study does not refer to how teachers resist the reform requirement. It refers to how teachers, after receiving the reform mandates, find the paths to negotiate various changing needs and expectations from school, parents, reform authorities, as well as themselves.

The term "agency" is usually associated with individual action or intrapersonal consciousness. However, people live together in groups, communities, and societies. Thus, social cognitive theory (Bandura, 2006) differentiated the three forms of agency: individual, proxy, and collective. Collective agency refers to a group of individuals pooling their knowledge, skills, and resources together and acting in concert to shape their future (Bandura, 2000). The teaching profession entails two seemingly conflicting features, working in group and working alone in a classroom. Classroom teachers work in schools with peers, sharing the workplace and resources. Yet, teaching can easily be perceived as a lonely profession since teachers often work alone and rarely ask for assistance (Fullan, 1999). Teachers talk to each other but rarely talk about their practice. Personality traits such as "competitiveness, defensiveness about critics, and a tendency to hog resources" (Fullan \& Hargreaves, 1996, p5) often promote isolation. By adopting the notion of collective agency, this study attempts to understand the complex engagement between an individual teacher and his/her colleagues as well between physics teachers as a group and the reform environment. This necessarily evokes the notion of collective agency, which in the context of our study extended the focus to include examination of the combination of individual growth and institutional development. Therefore, we began from the assumption that both the physics teachers' intentions and immediate surroundings are considered critical to their perception of collective agency. Researchers have argued that teachers are the key agent in any school or curriculum reform implementation (Fullan, 1993; Fullan \& Miles, 1992; Fullan \& Hargreaves, 1996). The interdependent relationships between teachers' collective agency and reform implementation (Datnow, Hubbard, \& Mehen, 2002; Lasky, 2005) are therefore interpreted and discussed within a case in China.

\section{Methods and Procedures}

Bandura (2006) rejects methodological reductionism which implies that studying fundamental science at the micro-level will explain phenomena at the macro-level. Rather, he proposes a plurality of methodologies that studies the emergence of phenomena at multiple levels. The study of human agency, then, should encompass psychological principles, social determinants such as social norms, culture, families, peer relations, school systems, and social-economic 
life conditions as well as the "the subserving neurobiological principles governing the process of learning" (p. 169). Hence, Bandura envisions a methodology that could study the complexity of various factors that influence human agency. This methodology does not reduce phenomena to rudimentary relations but focuses on system-level emergence. This methodology does not reject particular methods or thoughts. In a sense, it is related to phenomenology as it studies the phenomena as it is (Aoki, 2005) and seeks meanings in the life world (Schwandt, 2003).

We note that a large body of literature on studies about human agency and collective efficacy used quantitative or meta-analysis approaches by laying out general pictures of different aspects of agency (e.g. Bandura, 1998; Elder Jr, 1994; Goddard \& Goddard, 2001;Goddard, Hoy, \& Hoy, 2000; Kurz \& Knight, 2004; Ross, Hogaboam-Gray, \& Gray, 2004; Ross \& Gray, 2006; Skaalvik \& Skaalvik, 2007). This study, on the other hand, employed an ethnographic approach (Palys \& Atchison, 2008) that include interviews, field notes, pictures, researchers' and teachers' reflective journals, and classroom observations, aiming to offer an in-depth analysis of the relations and mechanism among individual agency, collective agency and reform structures. This case study (Stake, 1995) was conducted in three high schools in an inner city in mid-eastern China. Selection of the three schools was based in part by research findings that collaborative activities/collective agency tend to emerge in high achieving schools (Goddard \& Goddard, 2001; Goddard, Hoy, \& Hoy, 2000; Rosenholtz's 1991). The three schools are key secondary schools in the city and possess decent reputation in terms of student academic performance. Thirteen physics teachers were recruited from three highly ranked secondary schools out of more than thirty secondary schools in the city. The three schools were assigned number 3, 5, and 7 by the researchers. The teachers' teaching experience ranged from 1.5 years to more than 20 years. Although this study focused on physics teachers, research data were also collected from administrators as Ross and Gray's (2006) suggested that "transformational leadership had an impact on the collective teacher efficacy" (p.179). The data corpus involves two sets. The first set was collected three months after the start of reform in the three selected schools. This data collection occurred over for a period of four months. Each week, visits were made to the three schools for physics lesson observation. Each school had three 40 minutes lessons weekly. Therefore, for the three schools had a total of 1920 minutes of physics lessons were observed. The other set of data was collected six months after the end of the first phase. This phase lasted for one month. The same frequencies of observations were made in the three schools for a total of 480 minutes physics lessons were observed. Face to face interviews were conducted with thirteen teachers in each phase. Each interview lasted around one hour. Teachers were also invited to write reflective journals upon their practice during the data collection phases. Their reflections were collected and used to examine their thoughts of the restrictions and motivations in their own practice under the reform context. The two sets of data were used to explore how the collective agency was exercised, transformed, or sustained.

\section{Findings and Discussions}

The data corpus was sifted, compared, and contrasted using the constant comparative methods (Lincoln \& Guba, 1985). We looked for teacher's group work, their collaboration and some of their professional history from interview transcripts and observation field notes, in order to make sense of how they were "pooling their knowledge, skills, and resources together and acting in concert to shape their future" (Bandura, 2006) as well as their capacity of recognizing the constitution of the group (Davies, 2000). The process sought to identify themes and patterns that occurred repeatedly. Then the initial themes were further tested by constantly comparing (Lincoln $\&$ Guba, 1985) with the data sets. The themes intended to address the research questions. During the data collection process, we defined physics teachers' collective agency by the criteria that more than one teachers work together to share their knowledge, resource, and skills for communal goals in relation to teaching, learning and adopting the reform. Collective agency is identified when teachers mention or refer to their group work in the interview transcripts. In addition, their practices were observed in order to further validate their claims.

Three key themes emerged and touched upon other themes as a response to the research question: How does collective agency help physics teachers to adopt and adapt to the reform and in turn, how does the reform shape physics teachers' collective agency?

- Collective agency helped physics teachers develop pedagogies and curriculum interpretations corresponding to the reform mandates.

- Collective agency helped physics teachers cope with uncertainties generated by the reform.

- Power hierarchies between novice and veteran teachers were reduced by the reform mandates.

The first two themes are in response to how collective teacher agency helped teachers in the reform while the last theme describes how the reform shaped theirs collective agency.

\subsection{Develop Pedagogies and Curriculum Interpretations}

The provincial and municipal educational departments held teacher professional development programs, aimed at helping teachers adopt the new curriculum. Most participants deemed the program not very helpful while a small number of teachers gave negative feedback on their experience with these programs.

Teachers gave similar reasons on why the programs were not very helpful: the programs placed greater weight on theories than on practice and focused on the differences between the current and the previous curriculum most of the time. It informed the teachers what the new curriculum is about, why they need to adopt it but failed to show them how 
to interpret and implement it. Teachers knew their destination but did not have maps and vehicles. Therefore, teachers were uncertain about what they were supposed to do in their teaching practice. Sun and $\mathrm{Li}$, two grade 10 teachers from No.5 Secondary claimed "we've learnt nothing from the program" because "it did not tell you what method to use in teaching the new curriculum". Due to the limitation of time and the complexity of situations that individual teachers were engaging in, teachers claimed that the suggestions on pedagogical changes were limited, narrow, shallow and infeasible. Many of them experienced difficulties and confusions in applying recommended teaching methods in the new curriculum.

Such difficulties and confusions led teachers to pool their knowledge and skills together searching for reform-appropriate pedagogies and physics knowledge understanding and interpretations. There were two forms of teacher's collaborative work, the physics department meeting and office discussions. Collective agency is often identified and associated with such collaborative work. Although in different forms, the three participant schools all devoted most of the department meeting time to discussions around the curriculum reform. In addition, the teachers 'physics offices at each grade often had their own forms of discussion around issues in the reform as well as their daily practice. The most often addressed issues were regarding pedagogy and disciplinary content. According to the interviewees, teacher collaboration provided an opportunity to establish a type of collective intelligence, which in turn nurtured individual advancement.

Researcher: do you apply the pedagogical suggestions that came out from the discussion (with other teachers)?

Ho: Yes. I feel it is helpful

R: how helpful were the suggestions for your teaching practice based on students' feedback?

Ho: It was helpful. After all, you are on your own when teaching; sometimes individual's idea was not necessarily the best. It has some merits; it also has defects. But when every teacher could air his/her opinions, all merits could be collected in this way and I think the lesson will become more wonderful. (interview excerpt 12)

Researcher: How helpful was the discussions (with other teachers)?

$\mathrm{Li}$ : It is very necessary. Sometimes you teach in your own way, but the results are not very satisfactory. You could learn from others' methods. A group of people communicate and discuss the issues. Someone who has gained very satisfactory results could share the story in the group. (interview excerpt 6)

Teacher's collective agency seems to play a complementary role to the government's professional development program. The program informed teachers about the reform structure while teacher collaboration set up scaffolding for teachers fit into and even modify such a structure. Teacher's collective agency offers a strategy to localize the unified reform mandates, which attends both to the teacher's expectations and the reform's vision.

As "agency is never freedom from discursive constitution of self" (Davies, 2000, p. 67) as well as immediate environment, recognitions of the important role of self and the environment is the key to stimulating agency within individual and a group. Agency, in this study, was initiated by the top-down change brought about by the Ministry of Education. Although the government provided support to encourage the transition of curriculum and pedagogy, discrepancies exist between the offered-supports and the needed-supports. Teachers were aware of the gaps among their capabilities to implement the reform in practice, the reform expectations, society's expectations, and student's needs. Such conditions drive teachers to evaluate their own capacity as well as the resources they can deploy. The awareness of self and the environment leads to changes in actions. It is an adaptive process in which the adapters are aware of self-constitutions and relevant social structures. Changing is often risky, especially when one is not clear about the direction and is too vulnerable to afford the consequences. As social creatures, teachers seek help from counterparts and unite together to form collective forces in the reform. Collective agency plays a role of mediating the structural change requirements and individual's capacities.

China, with a variety of local educational contexts and a one-party administration, created an environment for generating collective agency. The reform policy and mandate shifts come from the central or provincial government. Such shifts are often vague, abstract, and not applicable to local context. Teachers feel strange or overwhelming to reform requirements. There are needs to generate mediating tunnels to implement and compromise such requirements at local levels. Collective agency, then, has become one of the major bridges to help teachers interpret the policies and implement the reform into local context.

\subsection{Cope with Uncertainties}

Teaching profession is full of uncertainty because 1) teaching lacks of a knowledge base or technical culture. There are limited assessments for a given teaching method; 2) the nature of teaching centered on human relationships and involves predicting, interpreting and assessing others' thoughts (Helsing, 2007). Many researchers argued that increased uncertainties are the byproducts of curriculum reform (Friedman, 1997; Frykholm, 2004; Fullan \& Miles, 1992; Ponticell, 2003) because reforms render interactions even more complex, unpredictable, and difficult to monitor and manage. The Chinese case is no exception. According to teachers, the major source of uncertainties in teacher's practice was coming from the new Curriculum Standard and the College Entrance Examination Guidelines.

The Full Time Ordinary High School Physics Curriculum Standard [Curriculum Standard] (MOE, 2002) replaced The Full Time Ordinary High School Physics Teaching Programme [Teaching Programme] (MOE, 2000) in the reform as the new skeleton of the curriculum. In the former curriculum, Teaching Programme, simply put, is a detailed 
interpretation of the textbook and guidance of teaching. It contained requirements of high school physics knowledge and concepts. It laid out specifically what should be taught and how deep it should be taught. Tests, exercise books, teacher's lesson plans were generated based on the Teaching Programme. The Curriculum Standard, on the other hand, is a standard for designing textbooks (Zhu \& Kang, 2002). It is a general frame of textbook content and lays out the educational goals of each discipline. However, most teachers considered the Curriculum Standard a counterpart of the Teaching Programme and found it vague and general in terms of directing teaching. Thus, lack of detailed instructions for teaching became one source of the uncertainties in teacher's daily practice.

The new curriculum also created uncertainties for the directions of the College Entrance Examinations (CEE). Working in an exam-driven education system for years even decades, teachers lost directions without the CEE guideline. Zhao and Zheng, physics department heads of No.7 and No.3 Secondary Schools respectively, shared similar views that the schools and teachers were judged by the society through CEE performance and the newly proposed evaluation system generated uncertainties among teachers.

...there is one issue, teachers are still evaluated by (students') test scores. Even though the school requires teachers to use the new curriculum, in reality, teachers still emphasize on knowledge and test skills because the higher the scores are, the more the society appreciates. But the new curriculum ask teaches to cultivate student's all-rounded capacity. ...teachers still have concerns over implementing the new curriculum. (Zhao interview excerpt 3 )

The rumor is that there is going to be a comprehensive evaluation which connected CEE. But no information about the connection with CEE. Most teachers feel it's still up in the air... (Zhao, interview excerpt 3)

The uncertainties in teacher's minds created barriers of implementing the new curriculum.

Exercising collective agency became the strategy to address uncertainty. Both individual teachers and their school sought help from group working. Individual teachers shared their interpretation of the Curriculum Standard by developing a common understanding.

Since using the new textbook, many teachers feel the content is not enough for the CEE. The CEE guide hasn't been issued yet nor the teacher's guide. Teachers don't feel safe to just rely on the new textbook. ...we [physics teachers in this school] work together and negotiate what to teach. It feels safer because, on the one hand, collective wisdom is better than individual's; on the other hand, you know, the law fails where violators are legion [a Chinese idiom] (Xu, interview excerpt 7).

Meanwhile, physics department heads collected teachers' collective suggestions for the CEE and hoped to be heard by reform authorities and policy makers. Teacher collective agency, as an approach to transmit teachers' voice to administration was stimulated by teachers' desire to see the CEE reformed consistent with the new curriculum. Twelve teachers shared the opinion that a successful reform requires corresponding changes in the CEE.

Teachers exercised collective power to seek psychological safety and to decrease risks of misinterpreting the Standard and misusing pedagogies. Teachers are considered to be responsible for their students' performance in the CEE. They were under great exam pressure especially when the guideline has not been released yet. The collaboration could reduce the risk by sharing the personal interpretation and referring to the collective opinion. Many teachers mentioned that they often discuss with other teachers when they interpreted the curriculum or experimented with new pedagogies. Frideman (1997) argues that groups can foster collective defense systems by providing emotional support, which can prevent teacher from confronting uncertainty and doing real work.

Researchers (Helsing, 2007; Ponticell, 2003) suggested two kinds of strategies that could deal with uncertainties: increase certainties by setting up regulations, rules, and policies and decrease uncertainties by encouraging teacher reflection and collaboration. In our case, collective agency played roles of amplifying teachers' demands and soothing teachers' psychological anxieties. With emotional support from colleagues, teachers are bolder to implement new strategies and pedagogies in their practice. The secureness of mind warrants the consistency in teaching actions, which maintains the reforming process in schools. Collective agency amplifies teacher's needs and appeals such needs to policy makers.

\subsection{Reduce Power Hierarchy}

The new curriculum played a critical role in reducing the hierarchical divide between experienced and novice in the process of forming collective agency, whereby the former were willing to share their concerns and problems in teaching with inexperienced (novice) teachers. Mandzuk, Hasinoff \& Seifert (2003) claim that "cohorts may exacerbate the influence of an agent who already dominates class discussions" (p. 170). Fullan and Hargreaves (1996) suggested that the teacher interactions could develop to balkanization. The power differential between the experienced and novice teachers can undermine the neighborhood interactions which refer to the interactions between "ideas, hunches, queries and other manners of representation" (Davis \& Simmt, 2003, p.156). This is especially the case in China, where culture and traditions stress power hierarchy governed by emphasis on respect and obedience for teachers and elders. Experienced teachers assume a higher status within a teacher community. They are expected to give advice and guidance to novice teachers rather than collaborate with them. When experienced teachers encounter a problem in teaching, they likely turn to even more experienced teachers and elders for guidance. Novice teachers, on the other hand, are expected to accept experienced teachers' advice without questioning and challenging. Novice teachers' opinions often are considered naïve. Thus, a teacher cohort in a school is easily becoming a 
group dominated by several experienced teachers, and the learning potentials of the collective are undermined in this way.

The participants of the study consisted of 7 novice teachers with no more than 5 years' teaching experience and 6 veteran teachers whose teaching experience was around 20 years. Four novice teachers felt that they learned more from the veterans than from their novice colleagues. Two of the four teachers considered the experienced teachers as their role models. Another two teachers believed that they have learnt from both novice and experienced teachers. Most novice teachers viewed experienced teachers as knowledgeable in pedagogy, skillful in classroom management, and patient in classroom. Senior teachers were good at improving students' performance on tests. They had mastered strategies that help students develop better arithmetic skills, memorize concepts, and were familiar with exam physics knowledge. According to one teacher's interview, students gained more satisfactory learning outcomes in experienced teachers' classrooms based on her observation. However, the better student performance and the gap between experienced and novice teachers' teaching experience were not a barrier to the collaboration. The self-organized physics teacher cohorts lasted for nearly two years and still serving the purpose of improving teaching. Most teachers found the cohort to be very helpful in terms of developing effective pedagogy and producing better learning outcomes. Zhang explains why she thought the power difference between experienced and novice teachers did not hinder the collaboration:

We have pressures in planning lessons. There is no previous reference for us in teaching, because all of us implement this curriculum at the same time, including the senior teachers. They are experienced in teaching, but their experiences are more relevant to the old curriculum. Therefore, in front of the new curriculum, we are all blind children. No reference. Even though we use cases in trial districts for reference, we need to find our own path. To this extent, we have to explore by ourselves. (Interview excerpt 2)

Zhang's claim was supported by some experienced teachers. Wei felt that some novice teachers' ideas and pedagogies were fresh. He was often inspired by their thoughts about teaching. Chen and Qian considered that each member in the group as having merits and benefited both novice and experienced teachers. In one of Qian's classes, the topic was the application of sensors. Qian used the example of photoelectric mouse in the textbook to illustrate a type of light sensor. Then a student asked the mechanism of a laser mouse. Qian hesitated for a while and said "I am not sure"... In the interview after class, Qian admitted that he had insufficient knowledge in high-tech and pop-culture. He pointed out that young teachers have abundant current knowledge which he can learn from. Some veteran teachers felt that it was easier for novice teachers to accept the new curriculum ideas and concepts and change their pedagogy.

Lv, a second year physics teacher, thinks that experience gave teachers advantages in successful teacher-student relations while Zhao, a physics teacher with 25 years' experience, believed otherwise.

Lv: It is difficult in communication with students about their learning. You have to admit that students tend not to trust young teachers. It is a FACT. It is a problem that I have to face. Once students have the feeling of distrust, they start to alienate you and it becomes harder for you to teach. (interview excerpt 9)

Zhao: For old teachers like us, it is hard to change. If you change the way you did for 20 years, you feel uncomfortable, don't you? The new curriculum suggests an equal relation between teacher and student. Teacher's class could be interrupt by student at anytime... As an old teacher, I feel hard to accept these; whereas young teachers are easy to get along with students. It is easy for them to change the class form and education form. For old teachers, even though they want to change, it is hard to change the differences between student and teacher. The students cannot relax when they socialize with old teachers and the old teachers don't know how to deal with this either. After all, they cannot fiddle with us like they did with young teachers. It is a limitation for old folks. (interview excerpt 5)

Although both teachers only saw their weaknesses and overlooked their strength in dealing with student relations, this state of mind created a climate conducive for collaboration. The curriculum requirement-shifting from a teacher-centered to student-centered classroom-conflicted with the teachers' existing beliefs about classroom pedagogies and thus wobbled the existing hierarchical structure between the veteran and novice teachers.

The veteran teachers' experience was an asset but not enough to successfully implement the new curriculum. Thus their previous status was challenged within a group, which created in them a willingness to allow equal contribution from all the members of the group. On the other hand, novice teachers became bolder in implementing the new curriculum. They saw everyone to be making valuable contribution where no one had the experience. The new curriculum offered the novice teachers opportunities to become more successful than the experienced teachers, hence building confidence. They did not hesitate to offer their opinions in front of all the group members. The fact that they saw their opinions were valued, strengthened their confidence, which undermined the dominant roles of veteran teachers in group work. It became evident that the democratic space flourished in the group. The dynamics of interpersonal relations have been changed in a way that promote teacher's collective agency.

Collective agency is defines as a group of people pool their knowledge, skills, and resources together and acting in concert to shape their future (Bandura, 2000). Hog resources, balkanism, and lack of communal goals were identified as factors undermining the "acting in concert" (Fullan, 1993). In the study, collective agency is likely weakened by power hierarchy, distrust among group members and traditional 
culture. The reform has created a communal goal for teachers and eliminates the power hierarchy among teachers. Turnbull's (2005) study showed that a positive and welcoming learning environment within the practicum context contribute to student teacher's agency practice. The collective agency, in this study, contributed to the rapport building among teachers and the rapport, in turn, contributed to a stronger community among physics teachers. Although experienced teachers tend to be more successful in terms of student performance in the reform, both experienced and novice teachers believe that they are novice to the reform and could learn from other members in the group. Such state of mind creates a dynamic collaborative work atmosphere which encourages each individual to share their skills, resources, and knowledge. The immense structural changes which are carried out from top-down wiped out the existing power structure in local communities and institutes. The uniqueness of Chinese context is the key to create such condition because it requires not only top-down structural change, but also grassroots who are willing to or accustomed to such political pattern.

\section{Conclusion and Implications}

The uniqueness of the Chinese reform context and the working culture nurtured physics teacher's collective agency to serve for the reform implementation. At the same time, the teachers' collective agency helped them to negotiate and transformed the reform implementation. Collective agency is generated and exercised when teachers meet unfamiliar challenges and such challenges are often beyond individual teacher's capacity to overcome. The challenges motivated teacher to work together and pool their skills, expertise, and resources together to achieve greater goal. By agreeing to meet together in groups to discuss their collective pedagogical issues, individual teachers could move out of their comfort zones or convert their roles in order to ensure effective collaborations. Such collaborations help teachers address common issue and generate psychological support in a community. Their collective efforts transformed professional culture as well as the reform implementation. The group collaborations form a stronger local community to cope with the reform mandates, challenges and at the same time, meet the specific needs of schools and students. Thus, the implementation process of the reform is not fixed but evolving because of teacher's collective agency constantly negotiates with the reform mandates and contexts. The interdependence relationships between agency and structure are specified in the Chinese reform case.

\section{References}

[1] Aoki, T. T. (2005). Toward Curriculum Inquiry in a New Key (1978/1980). In W. F. Pinar \& R. L. Irwin (Eds), Curriculum in a new key: The collected works of Ted T. Aoki., Studies in curriculum theory. (pp 89-110). Mahwah, NJ, US: Lawrence Erlbaum Associates Publishers.
[2] Bandura, A. (1998). Personal and collective efficacy in human adaptation and change, in Adair, J. G. (Ed,). Récents développements en psychologie scientifique (pp.51-71). Psychology Press.

[3] Bandura, A. (2000). Exercise of human agency through collective efficacy. Current Directions in Psychological Science, 9, 75-78.

[4] Bandura, A. (2006). Toward a Psychology of Human Agency. Perspectives on Psychological Science, 1(2), 164 -180. doi:10.1111/j.1745-6916.2006.00011.x

[5] Datnow, A., Hubbard, L., \& Mehen, H. (2002). Educational reform implementation: A co-constructed process. London: Routledge.

[6] Davies, B. (2000). A body of writing 1990-1999. Walnut Creek, CA: AltaMira

[7] Davis, B. \& Simmt, E. (2003). Understanding learning systems Mathematics education and complexity science. Journal for Research in Mathematics Education 34(2), 137-167.

[8] Elder Jr., G. H. (1994). Time, Human Agency, and Social Change: Perspectives on the Life Course. Social Psychology Quarterly, 57(1), 4-15.

[9] Erickson, G., Kang, C., Mitchell, I., \& Ryan, J. (2008). Role of teacher research communities and cross-culture collaboration in the context of curriculum reform in China. Samaras, A.P. et al. (Eds.), Learning communities in practice (pp179-191). Netherlands: Springer.

[10] Friedman, V. J. (1997). Making schools safe for uncertainty: Teams, teaching, and school reform. Teachers College Record, 99, 335-370.

[11] Frykholm, J. (2004). Teachers' tolerance for discomfort: Implications for curricular reform in mathematics. Journal of Curriculum and Supervision, 19(2), 125-149.

[12] Fullan, M. G. (1993). Change forces: Probing the depths of educational reform. London: The Falmer Press.

[13] Fullan, M. G. (1999). Change forces: The sequel. London: The Falmer Press.

[14] Fullan, M. G., \& Hargreaves, A. (1996). What's worth fighting for in your school? New York: Teacher College Press.

[15] Fullan, M. G., \& Miles, M.B. (1992) Getting reform right: What works and what doesn't. Phi Delta Kappan, 73(10), 745-752.

[16] Giddens, A. (1984). The constitution of society: Outline of the theory of structuration. Berkeley, CA: University of California Press.

[17] Goddard, R. D., \& Goddard, Y. L. (2001). A multilevel analysis of the relationship between teacher and collective efficacy in urban schools. Teaching and Teacher Education, 17(7), 807-818

[18] Goddard, R. D., Hoy, W. K., \& Hoy, A. W. (2000). Collective Teacher Efficacy: Its Meaning, Measure, and Impact on Student Achievement. American Educational Research Journal, 37(2), 479 -507.

[19] Guan, Q., \& Meng, W. (2007). China's New National Curriculum Reform: Innovation, challenges and strategies. Front. Educ. China, 2(4), 579-604. 
[20] Helsing, D. (2007). Regarding uncertainty in teachers and teaching. Teaching and Teacher Education, 23(8), 1317-1333.

[21] Kurz, T. B., \& Knight, S. L. (2004). An Exploration of the Relationship Among Teacher Efficacy, Collective Teacher Efficacy, and Goal Consensus. Learning Environments Research, 7(2), 111-128.

[22] Lasky, S. (2005). A sociocultural approach to understanding teacher identity, agency and professional vulnerability in a context of secondary school reform. Teaching and Teacher Education, 2005(21), 899-916.

[23] Lincoln, Y. S., \& Guba, E. G. (1985). Naturalistic inquiry. Newbury Park, CA: Sage.

[24] Mandzuk, D., Hasinoff, S., \& Seifert, K. (2003). Inside a student cohort: Teacher education from a social capital perspective. Canadian Journal of Education, 28, 1 \& 2, 168-184.

[25] Ministry of Education of the People's Republic of China. (2001). Outline of Curriculum Reform of Basic Education (trial version). (in Chinese)

[26] Ministry of Education of the People's Republic of China. (2003). Full-time High School Physics Curriculum Standard. (in Chinese)

[27] Palys, T. \& Atchison, C. (2008). Research decisions: Quantitative and qualitative perspectives ( $4^{\text {th }}$ Ed.). Scarborough, ON: Thompson Nelson.

[28] Pignatelli, F. (1993). What can I do? Foucault on freedom and the question of teacher agency. Educational Theory, 43(4), 411-432.

[29] Ponticell, J. A. (2003). Enhancers and inhibitors of teacher risk taking: A case study. Peabody Journal of Education, 78(3), $5-24$.

[30] Rosenholtz, S. (1991). Teachers' workplace: The social organization of schools. New York: Teacher College Press.

[31] Ross, J., \& Gray, P. (2006). Transformational leadership and teacher commitment to organizational values: The mediating effects of collective teacher efficacy. School Effectiveness and School Improvement, 17(2), 179-199.

[32] Ross, J., Hogaboam-Gray, A., \& Gray, P. (2004). Prior Student Achievement, Collaborative School Processes, and Collective Teacher Efficacy. Leadership and Policy in Schools, 3(3), 163-188.

[33] Skaalvik, E. M., \& Skaalvik, S. (2007). Dimensions of teacher self-efficacy and relations with strain factors, perceived collective teacher efficacy, and teacher burnout. Journal of Educational Psychology, 99(3), 611-625.

[34] Song, S. (Eds.). (2006). Senior High School Physics new curriculum: Ideology and teaching practice. Beijing: The Commercial Press. (In Chinese)

[35] Stake, R. E. (1995). The art of case study research. SAGE.

[36] Zhu, M., \& Kang, C. (2002). Approaching the new curriculum: Dialogues with curriculum participants. Beijing: Beijing Normal University. (In Chinese) 